\title{
Review Article \\ Role of Dopaminergic Receptors in Glaucomatous Disease Modulation
}

\author{
Nicola Pescosolido, ${ }^{1}$ Francesco Parisi, ${ }^{2}$ Paola Russo, ${ }^{2}$ \\ Giuseppe Buomprisco, ${ }^{2}$ and Marcella Nebbioso ${ }^{2}$ \\ ${ }^{1}$ Department of Cardiovascular, Respiratory, Nephrologic, Anesthesiologic and Geriatric Sciences, Sapienza University of Rome, \\ Piazzale Aldo Moro 5, 00161 Rome, Italy \\ ${ }^{2}$ Department of Sense Organs, Centre of Ocular Electrophysiology, Sapienza University of Rome, Piazzale Aldo Moro 5, \\ 00161 Rome, Italy \\ Correspondence should be addressed to Marcella Nebbioso; marcella.nebbioso@uniromal.it
}

Received 14 April 2013; Revised 6 June 2013; Accepted 12 June 2013

Academic Editor: Paolo Fogagnolo

Copyright (C) 2013 Nicola Pescosolido et al. This is an open access article distributed under the Creative Commons Attribution License, which permits unrestricted use, distribution, and reproduction in any medium, provided the original work is properly cited.

Both studies on animals and humans suggest the presence of dopamine (DA) receptors in the anterior segment of the eye. Their role in the dynamics of intraocular pressure (IOP) is not yet clear. $\mathrm{DA}_{2}$ and $\mathrm{DA}_{3}$ receptors are mainly located on postganglionic sympathetic nerve endings. Their stimulation reduces the release of norepinephrine and suppresses the production of aqueous humor. $\mathrm{DA}_{1}$ receptors seem to be more expressed by the ciliary body and the outflow pathway of aqueous humor. The administration of $\mathrm{DA}_{1}$-selective agonists stimulates the production of aqueous humor, increasing IOP, whereas $\mathrm{DA}_{2}$ - and $\mathrm{DA}_{3}$-selective agonists could reduce IOP and, therefore, the risk to develop a glaucoma (GL). GL is a broad spectrum of eye diseases which have in common the damage to the optic nerve and the progressive loss of the visual field. Further studies are desirable to clarify the role of the dopaminergic system and the usefulness of $\mathrm{DA}_{2}$ and $\mathrm{DA}_{3}$ agonists in reducing IOP.

\section{Introduction}

Biological basis of glaucoma (GL) are not yet fully understood, and the factors involved in its progression are not yet fully identified. The most important risk factor is high intraocular pressure (IOP), due to the reduction in the outflow of aqueous humor through the iridocorneal angle $[1,2]$. Other risk factors are aging (in elderly the prevalence of the disease is higher), family history, African-Caribbean race, high myopia (>4D), thinner cornea, lens pseudoexfoliation, low blood pressure (diastolic one in particular), and local and systemic vascular risk factors (optic disc hemorrhage or atrophy, vasospasm, etc.) [1-4].

Physiologically, IOP is regulated by a proper balance between secretion and drainage of aqueous humor. This is produced by ciliary body's epithelium into the posterior chamber from which passively diffuses into the anterior one through pupil [3-5]. Once in the anterior chamber, about $80 \%$ of aqueous humor outflows through the trabecular meshwork and then in a small vessel called Schlemm's canal.
Finally, through aqueous veins, it comes out from ocular bulb by episcleral veins and reaches the bloodstream. The remaining $20 \%$ of aqueous humor flows, independently from IOP, through the uveoscleral outflow or along nerves and small ocular vessels [4-7].

High IOP is one of the most important risk factors involved in GL and is the only one against whom actual therapies are really effective. Epidemiological studies showed that the risk of GL increases by $12 \%$ for each $1 \mathrm{mmHg}$ increase of IOP $[1,2,8]$. To date, GL is the second leading cause of blindness in the world [8]. GL can be congenital or acquired. The further classification in primary open-angle glaucoma (POAG) and primary angle-closure glaucoma (PACG) concerns the mechanisms that hinders aqueous humor outflow. In primary GL, the increase of IOP is not associated with other ocular disorders, while in secondary GL, a recognizable factor, ocular or nonocular one, alters the outflow of aqueous humor. In western countries, POAG is more common than PACG $[1,2,8]$. 


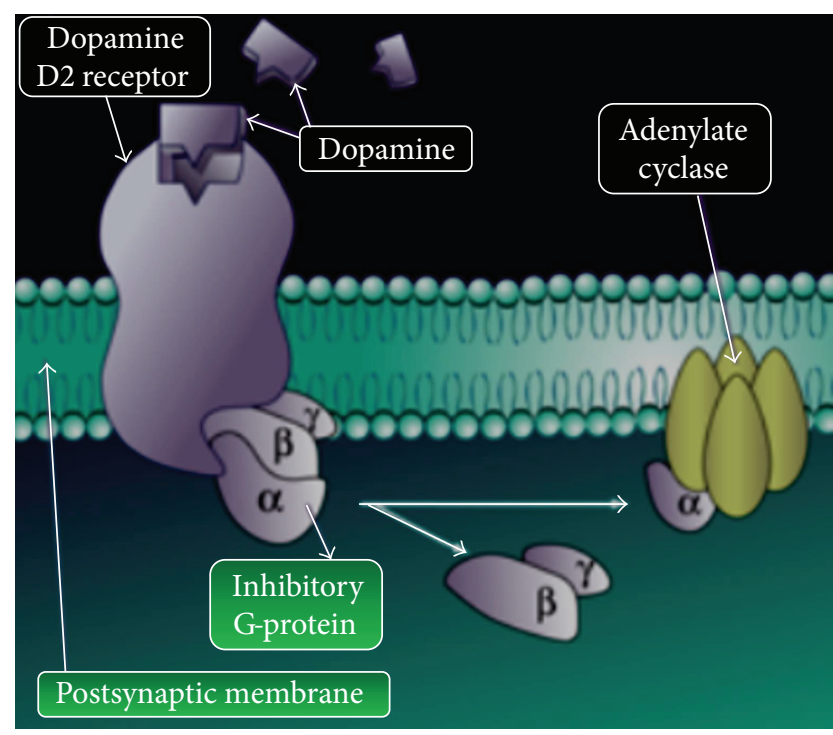

FIgURE 1: Structures of dopamine receptors $\left(\mathrm{DA}_{2} / \mathrm{DA}_{3}\right)$ and $\mathrm{G}$ protein coupled to receptors.

Molecular events responsible for GL are still for the most part unknown. Several molecules are able to regulate IOP: adrenergic, cholinergic, serotonergic, and dopaminergic systems are all involved.

Dopamine (DA) is a simple organic chemical in the catecholamine family released from postganglionic nerve fibers of the superior cervical dopaminergic ganglion in the aqueous humor [9-12] and exerts its action by binding to 5 different types of DA receptors $\left(\mathrm{DA}_{1-5}\right)$ which belong to the superclass of G-proteins coupled receptors.

DA receptors are grouped in two distinct families: $\mathrm{DA}_{1}$ like receptors (which include $\mathrm{DA}_{1}$ and $\mathrm{DA}_{5}$ receptors) and $\mathrm{DA}_{2}$-like receptors, like $\mathrm{DA}_{2}, \mathrm{DA}_{3}$, and $\mathrm{DA}_{4}$ [11-14]. The main difference between those families of receptors concerns the action of G-proteins: $\mathrm{DA}_{1}$-like receptor has a Gs-protein whose activation results in an increase of cyclic AMP (cAMP) mediated by adenylate cyclase $[9,10,12] . \mathrm{DA}_{2}$-like receptors are coupled to a Gi-protein which determines, instead, the inhibition of adenylate cyclase and, consequentially, a decrease of cAMP (Figure 1).

The aim of this review is to investigate, specifically, the dopaminergic influence on IOP to evaluate the role of new hypotensive drugs.

\section{Studies on Animals}

Early studies of the role of DA in GL on animal models led to contrasting results. Shannon et al. [15] showed that DA, administered topically, increases IOP in rabbit eyes, and haloperidol (DA inverse agonist) can contrast that action. Green and Elijah [16] noticed, by contrast, that IOP decreased during parenteral administration of DA, indicating that a different route of administration of DA produces different effects on IOP. In 1984, Potter et al. [17] studied the sequel of topical administration of DA and its methylated analogs: N-methyl-dopamine (NMDA), $\mathrm{N}, \mathrm{N}$-dimethyl dopamine (DMDA), and N,N-Di-n-propyl dopamine (DPDA) in eyes of healthy rabbits and of sympathectomized ones. Thus, in normal rabbits, DA, DMDA, and NMDA induced an increase of IOP unilaterally, while DPDA induced a bilateral hypotension after unilateral topical administration.

Furthermore, in sympathectomized rabbits they noted the following results:

(1) the administration of NMDA and DMDA produced an exaggerated ocular hypertension, followed by hypotension;

(2) the hypotensive effects of DPDA registered in normal rabbits eyes were absent in sympathectomized ones.

In summary, they assessed that DA and its analogues produce two different effects:

(A) a direct and postjunctional effect, mediated by DA agonists that bind to $\mathrm{DA}_{1}, \alpha$, and $\beta$ receptors;

(B) an indirect and prejunctional (or "neuronal") effect, mediated by DA agonists that bind $\alpha_{2}$ and $\mathrm{DA}_{2}$ receptors.

Green et al. $[9,16]$, studying rabbit's ciliary epithelium in vitro, observed that DA increases passive permeability and active secretion of aqueous humor. Both effects could be inhibited by $\alpha$ and $\beta$ antagonists, phentolamine, and sotalol, respectively, but not by a relatively selective DA antagonist (butaclamol) [18]. The secretory function of DA was subsequently confirmed by studies that identified, on nonpigmented epithelium of the ciliary body of animals and humans, the phosphoprotein $3^{\prime}-5^{\prime}$ monophosphate (DARPP-32) which regulates adenosine and DA systems [19].

Potter et al., however, showed that topical administration of some ergoline (lergotrile, pergolide) and an ergopeptide (bromocriptine), both in rabbits and monkeys, decreased IOP by acting on $\mathrm{DA}_{2}$ receptors $[17,20,21]$. The action of $\mathrm{DA}_{2}$ receptors was further confirmed by a subsequent study by Potter [12]. He noted a decrease hypotensive effect of ergoline in eyes of rabbits pretreated with domperidone (a $\mathrm{DA}_{2}$ antagonist) and surgical sympathectomy.

In summary:

(1) the decrease of IOP mediated by ergot derivatives is partly dependent to sympathetic neuronal activity;

(2) probably $\mathrm{DA}_{2}$ receptors are expressed in the sympathetic ganglion and/or sympathetic postganglionic nerveendings;

(3) ocular hypotension is just partially due to the inhibition of formation of aqueous humor. To further confirm that indirect effects are responsible for lowering IOP, Savolainen et al. [22] reported that selective $\mathrm{DA}_{2} / \alpha_{2}$ agonist like CHF1035 and its metabolite CHF1024, if instilled in rabbit's eyes, have similar effects to brimonidine in lowering IOP, but CHF1035 has a long lasting action too. 
These data suggest the presence of DA receptors in the anterior segment, but in order to better understand and investigate their role, it was important to precisely identify where the structures were present. Many biochemical, immunohistochemical and functional studies have been performed on animal tissue samples to find $\mathrm{DA}_{1}$ receptors localization, but not $\mathrm{DA}_{2}$ ones. $\mathrm{DA}_{1}$ receptors are present on ciliary body epithelium of bovine $[11,19]$ and on ciliary processes epithelium of rabbit $[9,15,18]$ confirming that their stimulation causes from one side an increased production of aqueous humor and, on the other hand, an altered outflow of it affecting the tone of ciliary muscle. $\mathrm{DA}_{2}$ receptors main localization seems to be the postganglionic presynaptic nerve ending [22].

In addition to the previously mentioned receptors, Chu et al. showed the involvement of a specific DA receptor, the $\mathrm{DA}_{3}$, responsible for IOP hypotonization in an animal model of rabbit [23]. Recently, some authors studied the hypotensive effect of 7-hydroxy-2-dipropilaminotetralina (7OH-DPAT), the main agonist of $\mathrm{DA}_{3}$ receptor on rabbit eyes [23], showing that

(1) IOP lowering effect of 7-OH-DPAT was due in part to the reduction of the production of aqueous humor;

(2) the nervous site of action of 7-OH-DPAT has been identified immunohistochemically as the $\mathrm{DA}_{3}$ receptor of ciliary body and has been associated with the decrease of hypotensive effects in rabbits deprived of sympathetic nerve endings;

(3) the inhibition of the hypotensive effect of 7-OHDPAT by $\mathrm{DA}_{3}$ receptor antagonists (U99194A and $\mathrm{UH} 232$ ) and the deprivation of postganglionic sympathetic endings, together with the immunohistochemical data, showed that the primary site of action of 7-OH-DPAT is located in the presynaptic postganglionic nerve endings of the ciliary body of rabbit eyes.

A similar study, conducted on mice, was performed by Bucolo et al. [14]. The authors observed that topical application of 7-OH-DPAT, $\alpha \mathrm{DA}_{3}$ preferring receptor against, significantly decreased in wild-type (WT) mice both in an ocular normotensive group and an ocular hypertensive steroid-induced group. Instead, there were no changes of IOP in $\mathrm{DA}_{3}$ receptor knockout mice. Moreover, genetic analysis conducted on ocular tissues of WT mice with PCR showed several genes encoding for all DA receptors but the absence of the receptor gene in $\mathrm{DA}_{3} \mathrm{KO}$ mice [14].

\section{Studies on Humans}

The expression of $\mathrm{DA}_{2}$ receptors in the anterior segment of the eye in humans has been confirmed by functional data, but there are no studies which revealed their localization.

Unlike $\mathrm{DA}_{2}$ receptors, $\mathrm{DA}_{1}$ have also been identified in human eyes [19] with biochemical and autoradiographic techniques using $[3 \mathrm{H}]-\mathrm{SCH}-23390$, a selective antagonist of $\mathrm{DA}_{1}$ receptor. $\mathrm{DA}_{1}$ receptors were present on uveoscleral tissue, trabecular meshwork, and ciliary processes [7]. Eleven eyes, enucleated because of trauma but with no involvement of the iridocorneal angle, were analyzed. Seven eyes were treated for GL, while four of them had a normal IOP. Although the sample size was very small, a higher response, due to $\mathrm{DA}_{1}$ receptors, was noticed in eyes with normal IOP [7].

Mekki et al. demonstrated, in a double-blind study, that in 8 healthy volunteers without IOP alteration treated with oral bromocriptine $(1.25 \mathrm{mg}$ ), IOP decreased (compared to placebo) at 3 and 4 hours after the administration, with no effects on systemic arterial pressure and on pupil's diameter $[24,25]$. These results were later confirmed by a study involving patients suffering from Parkinson's disease and POAG. In fact, a decrease in IOP occurred when levodopa was replaced by bromocriptine per os $(2.5 \mathrm{mg})$ [26]. This drug has effects on the production of prolactin, and Mekki et al. showed that the eye drops containing bromocriptine can reduce IOP compared to placebo [24, 25].

In a double-blind, randomized, and prospective study, IOP was measured in 24 healthy subjects at baseline and 2, 4 , and 6 hours after the instillation of topical timolol ( $0.25 \%)$ and bromocriptine $(0.05 \%)$. Both bromocriptine and timolol decreased IOP significantly from baseline with no difference between them at 2 and $4 \mathrm{~h}$, but, at $6 \mathrm{~h}$, bromocriptine was more effective than timolol [27].

Al-Sereiti et al. showed that the hypotensive effect of pergolide (25 micrograms orally) was antagonized by a pretreatment with oral domperidone $(15 \mathrm{mg})$, a $\mathrm{DA}_{2}$ receptor low-selective peripheral antagonist [28].

$\mathrm{DA}_{1}$ receptor agonists were topically administered (DA, ibopamine, fenoldopam, and 3B90) in a study performed on 20 patients with POAG [29]. The authors demonstrated that the increase of IOP after the administration of those molecules was not inhibited neither by the administration of haloperidol nor by already known hypotensive drugs. Just the administration of a selective $\mathrm{DA}_{1}$ agonist ( $\left.\mathrm{SCH}-23390\right)$ was capable to reduce IOP, confirming that those receptors are involved in determining IOP.

Karnezis et al. showed that intravenous administration of angiotensin II, norepinephrine, and fenoldopam increased IOP in human subjects by the stimulation of $\mathrm{DA}_{1}$ receptors [30]. Subsequently, it was confirmed that the stimulation by fenoldopam could alter the outflow of the aqueous humor increasing IOP [31].

Among $\mathrm{DA}_{1}$ receptor agonists, we can also include the 3,4-di-isobutyrrylester of N-methyldopamine, better known as ibopamine $[32,33]$. This widely studied molecule has the following pharmacological properties:

(1) it increases the production of aqueous humor stimulating $\mathrm{DA}_{1}$ receptors both in healthy eyes and in glaucomatous ones;

(2) it is a valid provocative test to study the efficiency of aqueous humor outflow pathways; in fact, in close relatives of patients with POAG, the instillation of ibopamine $2 \%$ causes an increase in IOP which would not occur in subjects without familiarity for POAG.

Those data explain that high IOP due to the administration of ibopamine is not caused by the increased production 


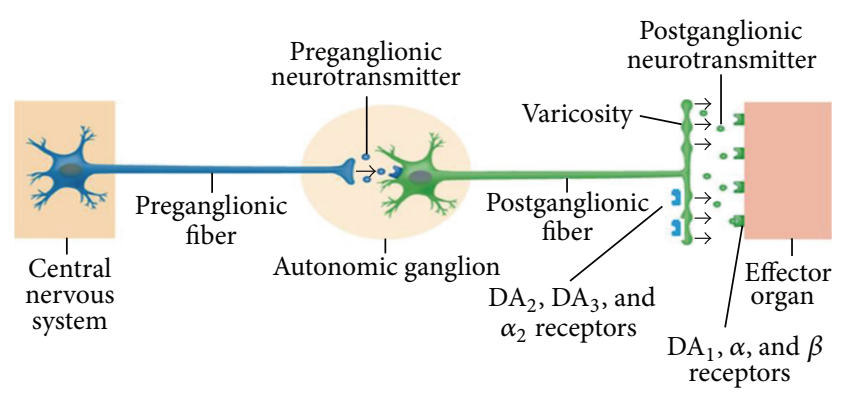

FIGURE 2: Prejunctional, indirect effects and postjunctional direct effects of dopamine (DA) and its analogues.

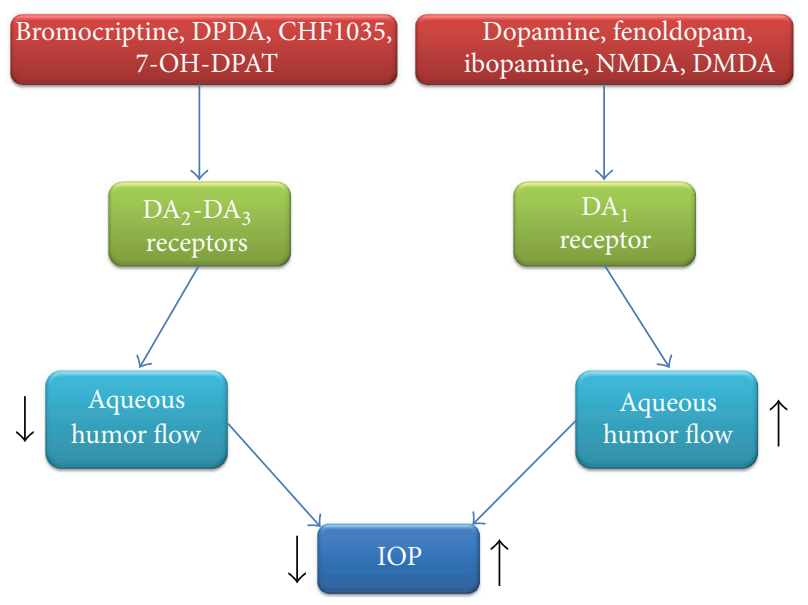

FIGURE 3: Effects of dopamine (DA) receptors on aqueous humor flow. DMDA: N,N-dimethyldopamine; DPDA: N,N-di-n-propyldopamine; NMDA: N-methyldopamine; 7-OH-DPAT: 7-hydroxy-2dipropylaminotetralin.

of aqueous humor but by an alteration of the outflow pathways [13, 32-34]. Ibopamine induces a cycloplegic mydriasis not acting on $\alpha$ receptors. Moreover, it can be used in hypotensive syndromes like anterior uveitis or damage of the ciliary body or after GL filtration surgery $[33,34]$.

Recently, Virno et al. [35] assessed the effect of ibopamine, a D1-dopamine agonist, on IOP in offsprings of parents with POAG as a consequence of outflow structures impairment. D1-dopaminergic stimulation due to ibopamine increases IOP as a result of increased production of the aqueous humor in participants with an impaired outflow. The study showed that after $2 \%$ ibopamine administration, there was a significant increase in aqueous humor production, both in glaucomatous and normal eyes. The intraocular hypertensive response due to ibopamine in normotensive eyes is a sign of initial outflow impairment and, therefore, a predisposition to intraocular hypertension and possible GL.

After this overview, we can conclude that the effects of DA and its analogs on IOP are complex: they can have both direct effects (postjunctional) and indirect (prejunctional) ones. The postjunctional effects of DA agonists can stimulate $\alpha, \beta$, and $\mathrm{DA}_{1}$ receptors. Similarly, indirect effects neuronal may be mediated by $\alpha_{2}, \mathrm{DA}_{2}$ and $\mathrm{DA}_{3}$ receptors (Figure 2).
In particular, $\mathrm{DA}_{1}$ agonists seems to increase the production of aqueous humor with a consequent increase of IOP, while, $\mathrm{DA}_{2}$ agonists are responsible of a decrease of IOP (Figure 3).

\section{Conclusions}

Although several classes of drugs are known to reduce IOP, just 5 of them are used in clinical practice. It is still necessary to look for the most powerful (and safer) therapeutic agent in order to reduce the serious consequences of GL. From the studies carried out on animals and humans, discussed previously, we can conclude that $\mathrm{DA}_{2}$, and $\mathrm{DA}_{3}$ agonists have an important influence on the modulation of IOP, with significant implications for the management of patients affected by GL.

Further studies are needed to clarify the role of the dopaminergic system and the usefulness of $\mathrm{DA}_{2}$ and $\mathrm{DA}_{3}$ agonists in lowering IOP.

\section{Conflict of Interests}

There are no potential conflict of interests or any financial or personal relationships with other people or organizations that could inappropriately influence conduct and findings of this study.

\section{References}

[1] H. A. Quigley and A. T. Broman, "The number of people with glaucoma worldwide in 2010 and 2020," British Journal of Ophthalmology, vol. 90, no. 3, pp. 262-267, 2006.

[2] H. A. Quigley, "Glaucoma," The Lancet, vol. 377, no. 9774, pp. 1367-1377, 2011.

[3] Y. Zhong, J. Wang, and X. Luo, "Integrins in trabecular meshwork and optic nerve head: possible association with the pathogenesis of glaucoma," Journal of Biomedicine and Biotechnology, vol. 2013, Article ID 202905, 8 pages, 2013.

[4] N. Pescosolido, C. Cavallotti, D. Rusciano, and M. Nebbioso, "Trabecular meshwork in normal and pathological eyes," Ultrastructural Pathology, vol. 36, no. 2, pp. 102-107, 2012.

[5] G. Scarsella, M. Nebbioso, S. Stefanini, A. Librando, and N. Pescosolido, "Degenerative effects in rat eyes after experimental ocular hypertension," European Journal of Histochemistry, vol. 56, no. 4, article e42, pp. 265-271, 2012.

[6] R. F. Brubaker, "Measurement of uveoscleral outflow in humans," Journal of Glaucoma, vol. 10, no. 5, pp. S45-S48, 2001.

[7] C. Cavallotti, N. Pescosolido, V. Pescosolido, and G. Iannetti, "Determination of dopamine D1 receptors in the human uveo scleral tissue by light microscope autoradiography," International Ophthalmology, vol. 23, no. 3, pp. 171-179, 2001.

[8] S. Kingman, "Glaucoma is second leading cause of blindness globally," Bulletin of the World Health Organization, vol. 82, no. 11, pp. 887-888, 2004.

[9] K. Green, A. Hensley, and G. Lollis, "Dopamine stimulation of passive permeability and secretion in the isolated rabbit ciliary epithelium," Experimental Eye Research, vol. 29, no. 4, pp. 423$427,1979$.

[10] B. Libet, "Which postsynaptic action of dopamine is mediated by cyclic AMP?” Life Sciences, vol. 24, no. 12, pp. 1043-1057, 1979. 
[11] M. D. Lograno, E. Daniele, and S. Govoni, "Biochemical and functional evidence for the presence of dopamine D1 receptors in the bovine ciliary body," Experimental Eye Research, vol. 51, no. 5, pp. 495-501, 1990.

[12] D. E. Potter, "Do dopamine and dopamine receptors have roles in modulating function in the anterior segment? The evidence," Progress in Retinal and Eye Research, vol. 15, no. 1, pp. 103-111, 1996.

[13] C. Prünte, I. Nuttli, R. Markstein, and C. Kohler, "Effects of dopamine D-1 and D-2 receptors on intraocular pressure in conscious rabbits," Journal of Neural Transmission, vol. 104, no. 2-3, pp. 111-123, 1997.

[14] C. Bucolo, G. M. Leggio, A. Maltese, A. Castorina, V. D’Agata, and F. Drago, "Dopamine-3 receptor modulates intraocular pressure: implications for glaucoma," Biochemical Pharmacology, vol. 83, no. 5, pp. 680-686, 2012.

[15] R. P. Shannon, A. Mead, and M. L. Sears, "The effect of dopamine on the intraocular pressure and pupil of the rabbit eye," Investigative Ophthalmology, vol. 15, no. 5, pp. 371-380, 1976.

[16] K. Green and D. Elijah, "Drug effects on aqueous humor formation and pseudofacility in normal rabbit eyes," Experimental Eye Research, vol. 33, no. 3, pp. 239-245, 1981.

[17] D. E. Potter, J. A. Burke, and F. W. Chang, "Alteration in ocular function induced by phenylethylamine analogs of dopamine," Current Eye Research, vol. 3, no. 6, pp. 851-859, 1984.

[18] R. Mancino, L. Cerulli, A. Ricci, and F. Amenta, "Direct demonstration of dopamine D1-like receptor sites in the ciliary body of the rabbit eye by light microscope autoradiography," Naunyn-Schmiedeberg's Archives of Pharmacology, vol. 346, no. 6, pp. 644-648, 1992.

[19] R. A. Stone, A. M. Laties, H. C. Hemmings Jr., C. C. Ouimet, and P. Greengard, "DARPP-32 in the ciliary epithelium of the eye: a neurotransmitter-regulated phosphoprotein of brain localizes to secretory cells," The Journal of Histochemistry and Cytochemistry, vol. 34, no. 11, pp. 1465-1468, 1986.

[20] D. E. Potter and J. A. Burke, "Effects of ergoline derivatives on intraocular pressure and iris function in rabbits and monkeys," Current Eye Research, vol. 2, no. 5, pp. 281-288, 1983.

[21] D. E. Potter and J. A. Burke, "An in vivo model for dissociating alpha 2-and DA2-adrenoceptor activity in an ocular adnexa: utility of the cat nictitating membrane preparation," Current Eye Research, vol. 3, no. 11, pp. 1289-1298, 1984.

[22] J. Savolainen, J. Rautio, R. Razzetti, and T. Järvinen, "A novel D2-dopaminergic and alpha2-adrenoceptor receptor agonist induces substantial and prolonged IOP decrease in normotensive rabbits," The Journal of Pharmacy and Pharmacology, vol. 55, no. 6, pp. 789-794, 2003.

[23] E. Chu, T.-C. Chu, and D. E. Potter, "Mechanisms and sites of ocular action of 7-hydroxy-2- dipropylaminotetralin: a dopamine3 receptor agonist," Journal of Pharmacology and Experimental Therapeutics, vol. 293, no. 3, pp. 710-716, 2000.

[24] Q. A. Mekki, S. M. Hassan, and P. Turner, "Bromocriptine lowers intraocular pressure without affecting blood pressure," The Lancet, vol. 1, no. 8336, pp. 1250-1251, 1983.

[25] Q. A. Mekki, S. J. Warrington, and P. Turner, "Bromocriptine eyedrops lower intraocular pressure without affecting prolactin levels," The Lancet, vol. 1, no. 8371, pp. 287-288, 1984.

[26] A. Lustig, "Does bromocriptine enhance the effect of drugs that reduce intraocular pressure?" Deutsche Medizinische Wochenschrift, vol. 108, no. 43, pp. 1656-1657, 1983.
[27] O. Elibol, C. Güler, K. Arici, A. Topalkara, and S. Demircan, "The determination of additive effect and intraocular pressure lowering effects of $0.05 \%$ bromocriptine and $0.25 \%$ timolol," International Ophthalmology, vol. 20, no. 1-3, pp. 53-55, 1997.

[28] M. R. Al-Sereiti, R. F. P. Quik, A. Hedges, and P. Turner, "Antagonism by domperidone of the ocular hypotensive effect of pergolide," European Journal of Clinical Pharmacology, vol. 38, no. 5, pp. 461-463, 1990.

[29] M. Virno, A. Gazzaniga, L. Taverniti, J. Pecori Giraldi, and F. de Gregorio, "Dopamine, dopaminergic drugs and ocular hypertension," International Ophthalmology, vol. 16, no. 4-5, pp. 349-353, 1992.

[30] T. A. Karnezis, M. B. Murphy, R. R. Weber, K. S. Nelson, B. J. Tripathi, and R. C. Tripathi, "Effects of selective dopamine-1 receptor activation on intraocular pressure in man," Experimental Eye Research, vol. 47, no. 5, pp. 689-697, 1988.

[31] J. R. Piltz, R. A. Stone, S. Boike et al., "Fenoldopam, a selective dopamine-1 receptor agonist, raises intraocular pressure in males with normal intraocular pressure," Journal of Ocular Pharmacology and Therapeutics, vol. 14, no. 3, pp. 203-216, 1998.

[32] C. Prünte and J. Flammer, "The novel dopamine D-1 antagonist and D-2 agonist, SDZ GLC-756, lowers intraocular pressure in healthy human volunteers and in patients with glaucoma," Ophthalmology, vol. 102, no. 9, pp. 1291-1297, 1995.

[33] L. Magacho, F. E. Lima, M. L. Costa, F. A. Fayad, N. L. Guimarães, and M. P. Avila, "Ibopamine provocative test and glaucoma: consideration of factors that may influence the examination," Current Eye Research, vol. 28, no. 3, pp. 189-193, 2004.

[34] I. F. Hepsen, H. Yilmaz, and U. C. Keskin, "The comparison of topical ibopamine $2 \%$ with tonography to identify the outflow resistance in eyes with ocular hypertension," Ophthalmic Research, vol. 37, no. 1, pp. 17-22, 2005.

[35] M. Virno, R. Sampaolesi, J. Pecori Giraldi et al., "Ibopamine: D1dopaminergic agonist in the diagnosis of glaucoma," Journal of Glaucoma, 2011. 


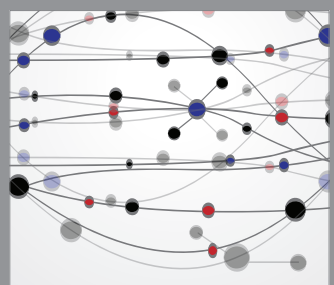

The Scientific World Journal
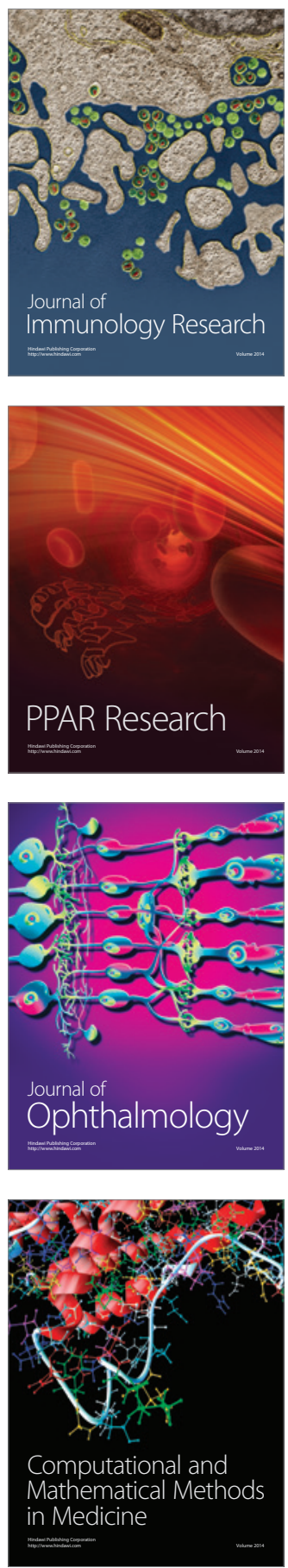

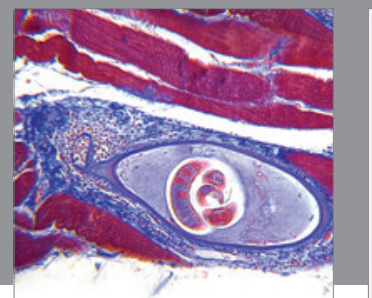

Gastroenterology

Research and Practice
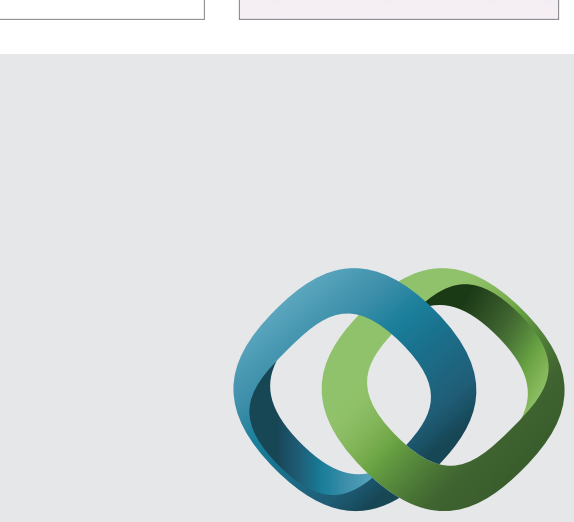

\section{Hindawi}

Submit your manuscripts at

http://www.hindawi.com
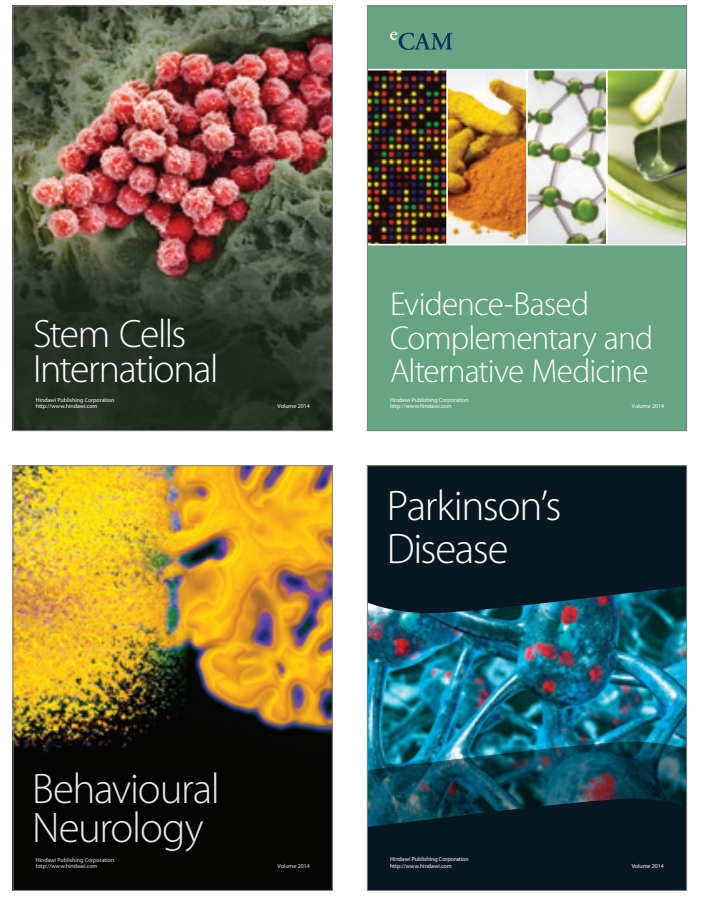
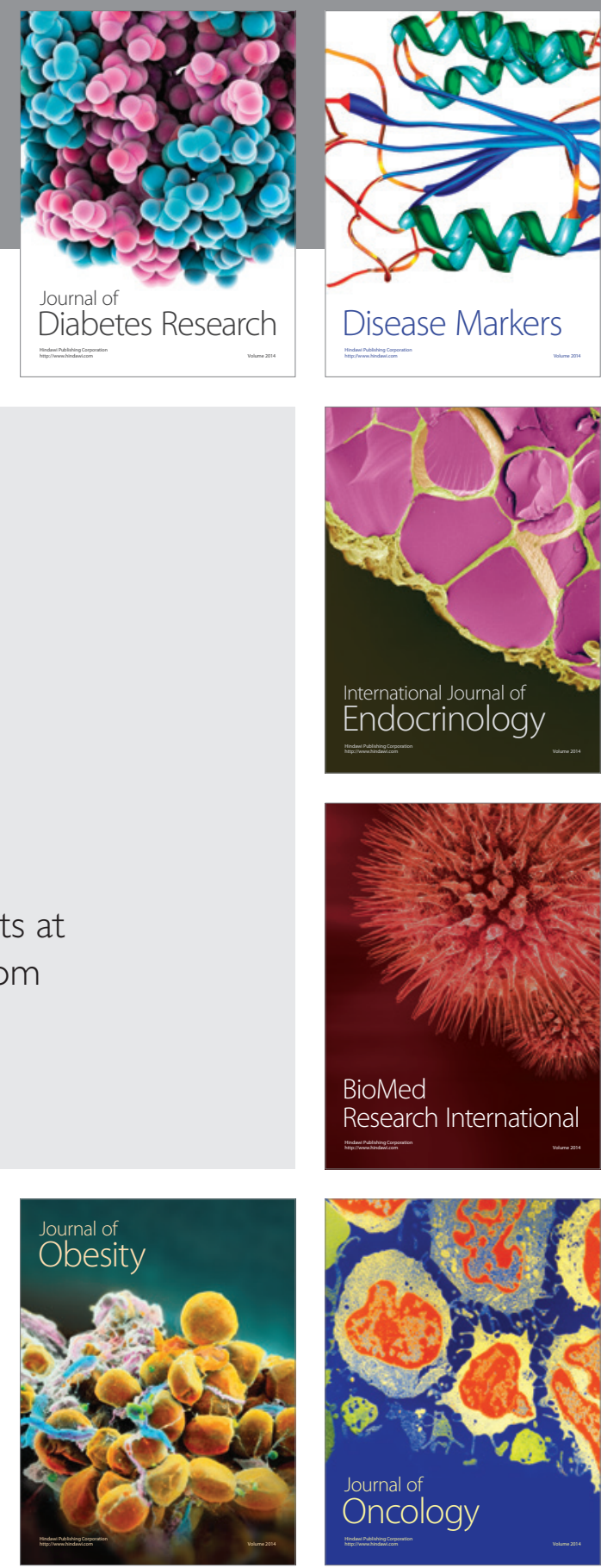

Disease Markers
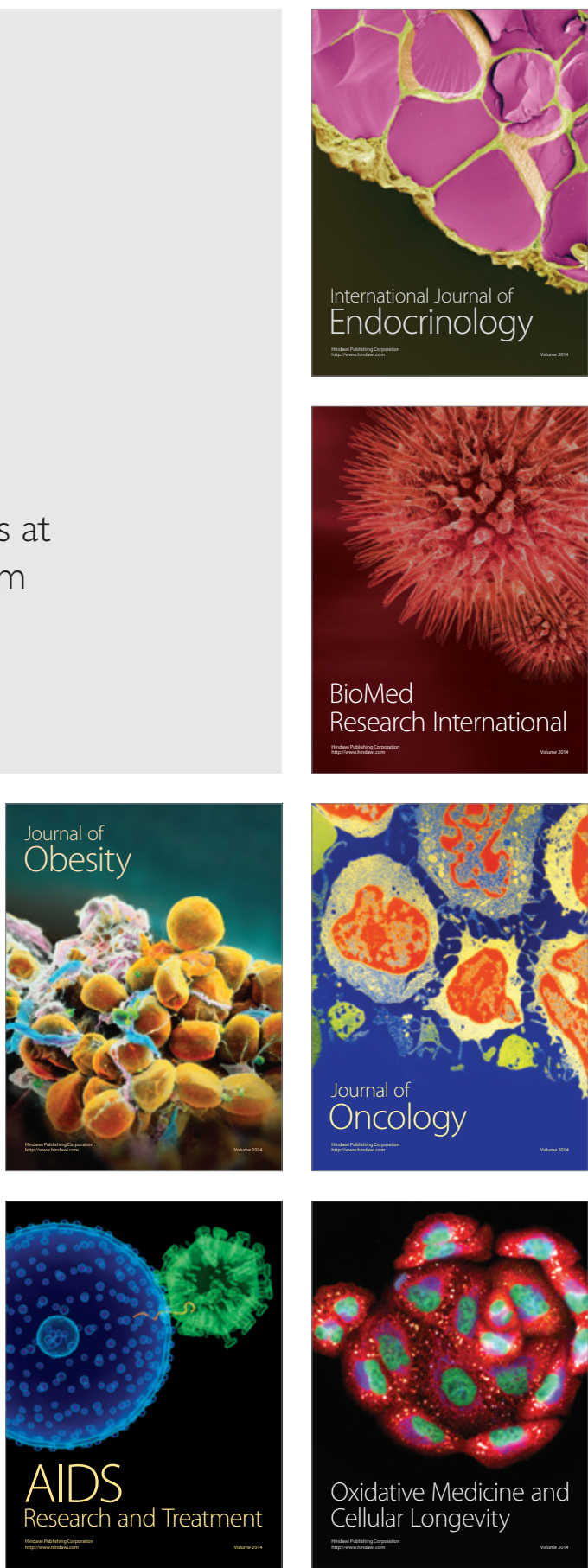